\title{
O Iberismo como primitivismo: a abordagem de José Marianno Filho
}

[ The Iberism as primitivism: the interpretation of José Marianno Filho

\author{
Ana Koury
}

Resumo - Este trabalho explora a interpretação de José Marianno Filho sobre a herança ibérica colonial brasileira. Apresenta seu programa da casa tradicional brasileira e da cidade brasileira como elemento fundamental de sua narrativa construída na década de I920 e registrada nas páginas de $O$ Jornal. A hipótese é que o autor abordou o Iberismo como um primitivismo, isto é, uma reação cultural em relação ao ecletismo, que resultou na busca da essencialidade na qual se afirmou depois o modernismo brasileiro. PalavrasCHAVE - José Marianno Filho; arquitetura brasileira neocolonial; Iberismo. AвSTRACT .
This work explores José Marianno Filho's interpretation of the Brazilian colonial Iberian heritage. He presents his program of the traditional Brazilian house and the Brazilian city as fundamental elements of his narrative built in the I920s and recorded in the pages of $\mathrm{O}$ Jornal. The hypothesis is that the author approached Iberism as a primitivism, that is, a cultural regression in relation to eclecticism, which resulted in the search for the essentiality in which Brazilian modernism was later asserted. KEYwords . José Marianno Filho; brazilian neocolonial architecture; iberism.

Recebido em 02/08/202I

Aprovado em 24/09/202I

KOURY Ana. O Iberismo como primitivismo: a abordagem de José Marianno Filho. Revista do Instituto de Estudos Brasileiros, Brasil, n. 80, p. I28-I4I, dez.202I.

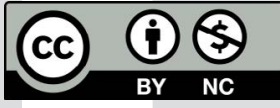

DOI: https://doi.org/Io.II606/issn.23I6-90IX.vIi8opI28-I4I

I Universidade São Judas (USJT, São Paulo, SP, Brasil). 
A cultura moderna da primeira metade do século XX buscou uma nova relação entre o sistema social-produtivo e o sistema cultural-simbólico. O resultado foi uma ideologia compatível com o desenvolvimento das forças produtivas, cuja identidade era, exatamente, a ruptura com o passado. No campo da arte, da arquitetura e das artes menores, isso seria materializado pela abstração e pela ausência do ornamento que caracteriza o movimento moderno.

O processo de constituição de uma nova identidade para a arte e a arquitetura da era moderna passou por uma espécie de "volta às origens", sendo precedido por um movimento em direção ao primitivo e ao essencial. Esse movimento procurou restituir a relação harmônica originária entre o homem, a vida e a arte e, com isso, reunificar sobre novas bases estéticas o sistema produtivo material e a produção cultural da paisagem, da arquitetura e dos objetos da vida cotidiana. Portanto, o primitivismo realizou a ruptura estética e a emancipação cultural em relação ao historicismo, e permitiu a afirmação do "moderno", compreendido como "novo" em relação ao "tradicional". Na Europa, o medievalismo romântico do final do século XIX precipitou esse processo em direção à essencialidade expressionista que conduziria ao modernismo. Na teoria estética, esse processo é descrito por Wilheim Worringer (I959, p.76), ainda em I9I9, para explicar a arte nova na Alemanha². Essa é a genealogia mais aceita sobre a história do movimento moderno, proposta por Nicolaus Pevsner, ainda em I936.

Muitos trabalhos têm lançado luz a esse processo no Brasil e apontado a variedade de movimentos que se aglutinaram na denominação de neocolonial, escrutinando amplamente suas relações com o modernismo brasileiro (AMARAL, I994; PUPPI, I998; MELLO, 2007; KESSEL, 2008; ATIQUE, 20I0; PINHEIRO, 20II).

O tema do primitivismo na conformação do modernismo brasileiro foi abordado por Guerra (20I0), que analisa esse conceito no debate intelectual a partir das obras de Mário de Andrade, Oswald de Andrade e Raul Bopp. Fundamentado na depuração do tipo brasileiro em autores como Paulo Prado, Graça Aranha e Guilherme de Almeida,

2 Antes de Worringer o revivalismo romântico na literatura do final do século I8 e início do século I9 recuperou o que era primitivo, selvagem, original e pinturesco como as principais glórias da vida (WESTLEND, I950, vol. IV, p. 20). 
Guerra apresenta o "homem triste” como homem primitivo. A interpretação desloca a origem do primitivismo moderno, nas vanguardas brasileiras, das correntes europeias para o pensamento brasileiro (GUERRA, 20Io).

O estudo do primitivismo no pensamento brasileiro realizado por Guerra (20I0) demonstrou a convivência entre passado e futuro, civilização e herança originária, e apontou um caminho para se investigar se o Iberismo neocolonial pode ser considerado uma forma de primitivismo em arquitetura. A análise fundamenta-se no fato de que o Iberismo, como apresentado por José Marianno Filho, busca na arquitetura tradicional uma forma essencial inspiradora da nacionalidade, em um projeto cultural e político de modernização liberal e conservadora que acabou deslocado pela Revolução de I930 e a ascensão do Varguismo.

\section{Iberismo e nacionalismo: o projeto de José Marianno Filho}

José Marianno Carneiro da Cunha Filho (I88I-I946) foi um dos mais ativos defensores do movimento neocolonial. Natural de Pernambuco, passou a infância no engenho Monjope, de sua família. Posteriormente, sua obra-modelo levaria esse nome (SANTOS, I977, p. 90; MAIOR; SILVA, I993, p. 76; BANDEIRA, 2008).

Ele se mudou com a família para o Rio de Janeiro no final da década de I890. Filho de pais abolicionistas, é difícil imaginar que José Marianno Filho - era assim que ele assinava as matérias publicadas em $O$ Jornal - tivesse uma visão idealizada do passado imperial e da herança colonial ibérica.

Seu pai, José Mariano Carneiro da Cunha, político influente, foi prefeito de Recife em I89I e deputado federal em I895. Formado na Faculdade de Direito do Recife, em I870, na mesma turma de Joaquim Nabuco, foi membro do Partido Liberal e fundador do jornal A Província, que divulgava as ideias do partido. Sua mãe, Olegária Gama Carneiro da Cunha, também se engajou na campanha abolicionista, acobertando a fuga de escravos que passavam por sua propriedade. Ela faleceu na mesma época em que a família se mudou para o Rio de Janeiro com os dois filhos: José Marianno e o irmão, Olegário Mariano, que se tornaria político e poeta (SANTOS, I977, p. 90; TELLES, I994; SCHUMAHER; BRAZIL, 2000, p. 455).

No Rio de Janeiro, José Marianno Filho formou-se em medicina, mas não exerceu a profissão. Seus interesses eram literatura, urbanismo e história brasileira. Trabalhou no Jardim Botânico, defendeu a integração entre a cidade e a natureza, chegando a propor uma legislação ambiental para proteger as encostas de morro que estavam em processo de ocupação. Participou da comissão de estudos de melhoramentos urbanos durante a gestão do prefeito Alaor Prata (I922-I926). Entendia a arquitetura como elemento essencial do ambiente, parte do habitat produzido pelo homem. Encontrou na arquitetura colonial ibérica um símbolo para a interpretação de seu projeto cultural nacionalista identificado ao neocolonial. José Marianno Filho também promoveu o neocolonial, patrocinando prêmios e viagens de estudo, entre I92I e I928. Em I92I, fundou o Instituto Brasileiro de Arquitetos e a Sociedade Central de Arquitetos, reunidos alguns anos depois no Instituto Central de Arquitetos. Dirigiu a Escola Nacional de Belas Artes entre junho de 1926 e maio de I927 e, por muitos anos, presidiu a Sociedade Brasileira de Belas Artes. Defendeu a arquitetura tradicional 
brasileira contra o ecletismo vigente por meio de artigos polêmicos e doutrinários publicados nos anos de I920 (SANTOS, I977, p. 90; TELLES, I994; KESSEL, 2008; MINGORANCE, 20I3).

Foi nesses anos que José Marianno Filho formulou sua interpretação da herança ibérica como parte de um programa nacionalista em sintonia com o quadro político do Brasil republicano. Em I930, as novas condições políticas e sociais do Brasil deram impulso à hegemonia do movimento moderno em arquitetura. O que não ocorreu repentina e linearmente, mas por via de uma longa e acirrada disputa nos campos da arte e da arquitetura. José Marianno Filho, que já havia enfrentado os defensores do ecletismo nos anos I920, agora nos anos I930 dirige sua crítica às primeiras manifestações do movimento moderno, em uma polêmica que toma vulto no IV Congresso Panamericano de Arquitetos, em I930, no Salão de Belas Artes do Rio de Janeiro, e no episódio que afasta Lúcio Costa da direção da Escola Nacional de Belas Artes, em setembro de I93I (SANTOS, I977, p. IOI-Io6; BRUAND, I98I, p. 52-59 e 7I-74; VIEIRA, I984; KESSEL, 2008, p. I9I-I97).

Nos anos 1940, dedica-se a reunir sua obra anterior e publicar seus estudos sobre a arte tradicional brasileira em forma de livros. Os artigos, muitos deles publicados pelos Diários Associados entre os anos I920 e I940, em O Jornal e na revista O Cruzeiro, foram selecionados e reunidos nos livros: Â margem do problema arquitetônico nacional e Debates sobre estética e urbanismo (TELLES, I994).

O projeto cultural e político de José Marianno Filho foi registrado principalmente no conjunto de artigos publicados nos anos de I920, nas páginas de $O$ Jornal, quando o autor se engajou na campanha contra o Ecletismo em defesa da cultura brasileira. A partir de I924, quando Assis Chateaubriand passou a dirigir o periódico, Marianno Filho ganhou um poderoso aliado, que se expressou publicamente a seu favor nos momentos mais polêmicos, em defesa da nacionalidade, da preservação ambiental e de sua atuação na Escola Nacional de Belas Artes (CHATEAUBRIAND, I926a; I926b; I927; I928).

Outro aliado de Marianno, em um projeto baseado na reinterpretação do passado ibérico, foi Fernando de Azevedo, redator do jornal O Estado de São Paulo entre I923 e I926. Azevedo organizou duas séries intituladas “inquéritos”, uma sobre arquitetura colonial, ilustrada por José Wasth Rodrigues e publicada em três partes, em abril de I926, e outra sobre educação, em São Paulo. Sua relação com a arquitetura, como ele mesmo esclarece, fazia parte de uma ampla estratégia de instrução pública sobre o tema da nacionalidade.

O culto à arte e à arquitetura do passado, integrado a uma campanha de instrução pública nacionalista, moveu ambos os personagens. Em I926, Marianno fazia parte do Conselho de Ensino Secundário Superior, e propôs a substituição da disciplina Sociologia do colégio Pedro II pela de História da Arte Brasileira (CONSELHO..., I926).

Em função de sua atuação em São Paulo, Azevedo foi chamado pelo prefeito do Rio de Janeiro, Antônio Prado Júnior, para liderar uma ampla reforma municipal do ensino público na cidade. Assim, assumiu o cargo de diretor da Instrução Pública do Distrito Federal, em janeiro de I927. A reforma do ensino municipal no Rio de Janeiro, empreendida por Azevedo, ficou conhecida como um dos programas mais inovadores da administração do ensino público, mas seu programa cultural no campo da arquitetura, ao contrário, ficou associado à vertente conservadora de Marianno. 
Azevedo instituiu o neocolonial como estilo oficial para os edifícios escolares, algo que já havia apontado em seu programa de ensino em I926 (AZEVEDO, I926; PILETTI, I994).

Posteriormente, já em I943, Azevedo publica A Cultura Brasileira, primeiro volume da série nacional de publicações do recenseamento geral do Brasil de I940. A obra inclui a história da arte, da arquitetura e da urbanização, dando grande ênfase ao projeto tradicionalista, ao movimento neocolonial e a José Marianno Filho. Lúcio Costa e a vertente modernista ocupam um espaço menor nessa obra, publicada quando Costa já havia assumido a seção de tombamentos do SPHAN, e o edifício-sede do Ministério de Educação e Saúde Pública no Rio de Janeiro, marco histórico do movimento moderno no Brasil, já havia sido inaugurado. Isso, em parte, explica a pouca atenção que o livro recebeu nas revisões historiográficas da arquitetura, mesmo naquelas dedicadas ao neocolonial. Azevedo e José Marianno Filho formularam um projeto cultural fundamentado na tradição ibérica como razão política para um projeto nacional, que se opunha ao modelo do Estado burocrático varguista.

A tradição ibérica como elemento fundamental na interpretação dos projetos políticos do Brasil moderno, como adotada neste artigo, foi discutida por Marco Aurélio Nogueira (2003) ao introduzir o debate entre Oliveira Vianna e Sérgio Buarque de Holanda. Nogueira apresenta uma tipologia do Iberismo dividida em três vertentes básicas. Uma vertente conservadora, que se opôs à modernização institucional do Brasil. Para essa vertente, o passado é uma forma de resistência para a conservação dos valores da tradição, da família e da propriedade. Essa vertente teve pouca expressão após a revolução de I930, ao contrário das outras, que conformaram um debate importante para a interpretação do modelo de nação em disputa nas décadas de vinte e trinta do século XX, e que voltaram ao centro do debate frente ao avanço do neoliberalismo no país.

Uma vertente importante de interpretação da herança ibérica é aquela que encontra no passado colonial a possibilidade de construção de um modelo social e institucional original e autônomo. Essa vertente aproveita os elementos culturais ibéricos estranhos ao liberalismo como uma forma de negociar a modernização brasileira, atenuando os efeitos nocivos dos excessos do individualismo e da competitividade presentes no modelo liberal americano. Estariam enquadrados nessa vertente autores como Richard Morse e Darcy Ribeiro, além das interpretações pioneiras de Gilberto Freyre e Sérgio Buarque de Holanda. (NOGUEIRA, 2003)

A terceira vertente de interpretação, na qual se enquadra a obra de Oliveira Vianna, reconhece o Iberismo como realidade cultural brasileira, responsável pela perpetuação de um modelo incompleto de nação, regido pela ordem clânica dos agrupamentos sociais primários ligados à formação rural no período da colônia. Para essa vertente, o Iberismo seria a razão política de uma utopia de Estado autoritário capaz de formar os elementos fundamentais de uma sociedade moderna: o indivíduo e as instituições. Essa razão utópica instrumental justificaria o autoritarismo de Estado em uma fase de transição para a modernização institucional da nação. $\mathrm{O}$ projeto autoritário de Oliveira Vianna foi elaborado entre as primeiras décadas do século XX e amadurecido nos anos 1940, dando respaldo ao Estado Novo (I937-I945) de Getúlio Vargas. Sua posição expressou uma ideia bastante difundida e apoiada 
por um conjunto de autores que escreveram nessa mesma linha de defesa do Estado autoritário (NOGUEIRA, 2003).

Partindo dessa tipologia de interpretação da cultura ibérica como interpretação e projeto de uma nacionalidade autônoma dos modelos importados, ou do cosmopolitismo internacional e abstrato representado por uma internacionalização sem mediações ou resistência cultural, este artigo procura investigar qual foi o projeto nacional e moderno de José Marianno Filho. Considerando que seus textos registram o debate em um momento de disputa, nos anos de I920, quando a revolução de I930 ainda não havia sido "vencedora" na batalha por um projeto nacional e moderno no Brasil, como o projeto de Marianno se enquadra nessa tipologia do pensamento Ibérico?

\section{A casa tradicional brasileira}

A casa deve possuir uma fisionomia própria, expressiva e inconfundível. Nela se refletem as tendências sociais da raça, os costumes, os hábitos regionais, em suma, a vida própria do povo. Para que uma arquitetura represente o pensamento do povo: para que ela possa representar o caráter da raça que ela vai servir, não basta que seja bela vestida de roupagens aparatosas. $\mathrm{O}$ arquiteto precisa ser antes de tudo sincero. Por isso a casa deve corresponder estritamente às necessidades do povo (MARIANNO FILHO, I927, p. 4).

Um dos valores mais repetidos por Marianno foi a essencialidade da arquitetura presente na casa tradicional brasileira. Sua função era servir como abrigo ao colonizador português e protegê-lo da natureza tropical hostil. Um exemplo de arquitetura primitiva e ponto de partida de um verdadeiro estilo brasileiro.

Publicado em I927, um dos discursos mais completos que registra a visão de Marianno ocorreu na colação de grau dos engenheiros-arquitetos da Escola Nacional de Belas Artes. Nele, Marianno despedia-se da direção da Escola, cargo que ocupou por aproximadamente um ano. Aconselhava os recém-formados a serem sinceros e a preservarem esses valores na arquitetura. Isso era uma crítica ao excesso ornamental, tanto do academicismo quanto do estilo missões.

Marianno foi um grande crítico desse estilo difundido na América Latina a partir do pan-americanismo e que retoma os elementos ornamentais da "arquitetura dos jesuítas”, preponderante na tradição hispânica. Sua crítica ao mission style, registrada em alguns artigos dessa época, atinge importantes arquitetos atuantes no período, como Christiano Stockler das Neves, Victor Dubugras, Archimedes Memória e Francisco Couchet. Sobre essa crítica, Marianno formulou um programa para a casa brasileira (MARIANNO, I92Ia; I925; I929b).

Embora questionando o valor artístico do estilo missões, José Marianno Filho incentivou o estudo do barroco brasileiro como parte da interpretação necessária para a renovação do passado em uma "arquitetura tradicional brasileira" em estilo neocolonial. Esse programa de estudo da arquitetura barroca no Brasil havia 
sido proposto ainda em I9I6 por Alceu Amoroso Lima e Rodrigo Mello Franco de Andrade, que viajam a Minas Gerais e voltam dispostos a organizar a preservação da arquitetura das cidades do período do ouro em Minas Gerais. Essas cidades foram preservadas pela decadência econômica e a transferência da capital para Belo Horizonte. No início do século XX, ainda guardavam em bom estado importantes exemplares do estilo barroco brasileiro, produzido no século XVIII. Nesse mesmo ano, Lima publica na Revista do Brasil o artigo "Pelo Passado Nacional”. Esse artigo daria as bases da recuperação do passado em um projeto nacionalista.

Na década de I920, Marianno propõe a criação de uma Inspetoria de Monumentos Públicos de Arte. Em I924, por meio da Sociedade de Belas Artes, financia a visita às cidades históricas de três jovens arquitetos, Lúcio Costa (Diamantina), Nestor Figueiredo (São João Del Rei) e Nereu Sampaio (Ouro Preto). Também no mesmo ano, os modernistas ligados à semana de I922 seguem para as cidades históricas de Minas: Mário de Andrade, Oswald de Andrade, Tarsila do Amaral, René Thiollier e o poeta francês Blaise Cendrars. A cronologia dos fatos demonstra que, embora o tema da preservação das cidades históricas e da importância do estudo do passado colonial fosse consenso entre a maioria das discussões modernizadoras e nacionalistas, o significado e a interpretação da tradição ibérica variaram de acordo com os diversos projetos para a nação (PINHEIRO, 2006, 20I7; KESSEL, 2008, p. I33).

O programa de renovação da "arquitetura tradicional brasileira" de Marianno foi doméstico, ou seja, antiornamental e antimonumental. Sua intenção foi transformar o neocolonial no gosto corrente de uma sociedade urbana de classe média, procurando definir, no programa da casa brasileira, um sistema completo de relação entre a cultura e a nacionalidade.

\section{O programa doméstico da casa tradicional brasileira}

A arquitetura de nossas casas não nos mudará o feitio de nossa própria alma. Os verdadeiros brasileiros, quando possuem uma casa à Luiz XVI, nem por isso deixam de ser brasileiros. E não seria de admirar que sob os lambris apainelados dos quartos de dormir a rede tapuya oscile docemente. Não vos envergonheis da arte de vossa raça, nem da língua heroica que falais, nem do sangue que vos corre nas veias (MARIANNO, I927, p. 4).

O programa da casa brasileira foi difundido em I92I com o prêmio Heitor de Melo para "habitação doméstica (...) constando de rés do chão e um pavimento superior em terreno de 20 metros de frente por 50 de fundo" (MARIANNO, I92Ib, p. 3). Os termos do prêmio e as exigências feitas por Marianno fornecem as pistas do caráter do programa doméstico da casa tradicional brasileira. Em carta a Gastão Bahiana, então presidente do Instituto de Arquitetos do Brasil, Marianno fez a doação para os três classificados na premiação, e esclareceu que o prêmio visava incentivar "a criação de um tipo de arquitetura nacional inspirada (...) no estilo tradicional, através do estudo das 'construções arquitetônicas sacras e civis' praticadas no Brasil 
durante o período colonial, sob a dominação artística dos missionários jesuítas." (MARIANNO, I92Ib, p. 3).

Marianno estabelece que tanto a casa como a ornamentação deveriam reproduzir as características da arquitetura colonial. Entre as ordens clássicas, restringe ao uso exclusivo da ordem toscana. A mão de obra deveria construir de acordo com a "práxis tradicional", isto é, tanto a produção da casa quanto a reprodução da ornamentação deveriam seguir rigorosamente a tradição e as técnicas do passado. Entretanto, o resultado deveria ser uma adaptação perfeita às condições de vida moderna e às exigências e posturas municipais, demonstrando a preocupação em criar um modelo compatível com a vida urbana da sua época.

Em I924, ele inaugura uma série de conferências na Sociedade Brasileira de Belas Artes sobre o tema "casa brasileira”. Descrita como proteção primitiva construída de acordo com as necessidades dos primeiros colonizadores, segurança contra a natureza tropical ameaçadora e núcleo de defesa de seu patrimônio (A CASA BRASILEIRA..., I924).

O jornalista que reporta o evento apresenta ao leitor as ideias de Marianno. A casa brasileira de Marianno inclui os elementos da vida familiar e patriarcal que constituíram uma nacionalidade de base patrimonial e doméstica em consonância com o projeto de modernização posteriormente registrado pela narrativa de Gilberto Freyre (I933) em Casa Grande e Senzala (BASTOS, 2000).

Remontou aos dias primitivos da nossa terra, em que a casa foi, antes de tudo, um baluarte, um refúgio contra a aspereza do meio selvagem, as feras bravias, as serpentes insidiosas, as jequitiranas sanguinárias, os marimbondos nada amáveis e o gentio furibundo - arco retesado e braço lesto na defesa do patrimônio de seus maiores.

(...) O orador diz já ter tido oportunidade de salientar a unidade do estilo arquitetônico dominante nas velhas cidades do Brasil colonial. Todas as casas são irmãs. Sente-selhes o 'ar de família'. Todas são amplas, bem plantadas, acolhedoras e sorridentes. Parece que nos convidam para o seu regaço.

(...) o movimento iniciado em favor da arquitetura tradicional é inspirado no mais sadio e puro nativismo. A casa brasileira surgiu do passado na singeleza da sua roupagem, na tranquilidade de suas linhas suaves e evocativas, para nos convencer mais uma vez de que uma raça só se afirma através do culto de seus legítimos valores sociais políticos ou artísticos (A CASA BRASILEIRA..., I924, p. 3).

Representou o elemento primitivo da arquitetura brasileira, capaz de promover a purificação das tradições, adequando-as à essencialidade necessária à fundação de novas bases culturais, importantes para o processo de modernização brasileira. A conferência também retomou o tema da arquitetura doméstica versus a arquitetura religiosa, presente em Arquitetura Tradicional, evocando suas raízes no romantismo inglês do século XIX (Marianno, I92Ia; A CASA BRASILEIRA..., I924).

Diz-se que a arquitetura tradicional é essencialmente religiosa. É um erro de apreciação. Se fôssemos julgar com igual critério a arquitetura dos demais países teríamos que, na Inglaterra, pátria do gótico, não só as grandes catedrais e os majestosos castelos, mas toda a arquitetura doméstica é fundamentalmente gótica (A CASA BRASILEIRA..., I924, p. 3). 
A fórmula da casa brasileira foi colocada em prática por Marianno no Solar Monjope, projetado com auxílio dos arquitetos Lúcio Costa, Angelo Burnhs e Nereu Sampaio - recém-saídos da ENBA -, construído no bairro da Gávea, no Rio de Janeiro, em I924, e demolido em I974 (ATIQUE, 20I6).

Marianno provavelmente inspirou-se em um solar português, cujo projeto ele adquiriu na Exposição de Arte Portuguesa, realizada na Escola Nacional de Belas Artes, em I920. Reproduziu no Solar as técnicas construtivas e os detalhes da arquitetura tradicional. Como defendeu no programa para a casa brasileira, também utilizou detalhes autênticos, amostras que colecionava da arquitetura colonial. Frequentemente recebia visitantes ilustres, como o urbanista francês Agache, que em I926 registrou a sua impressão do Solar:

Uma maravilha, cujo encanto é traduzido não só pela edificação, de linhas sóbrias e elegantes, mas pelas obras-primas d'arte antiga, em azulejos, murais, móveis de jacarandá, estátuas e peças de escultura em madeira, que esmaltam o interior, povoando os amplos salões do Solar de Monjope (Solar do Monjope, I927; p. 4).

O programa da casa brasileira proposto por Marianno guarda semelhanças com a recuperação romântica do final do século XIX, na Inglaterra, o movimento arts and crafts, de William Morris. Ambos partem de um conceito doméstico e essencialista ligado às tradições construtivas locais, que permitia reunir o que a sociedade industrial havia separado, isto é, o sistema construtivo (a arquitetura), o sistema ornamental (as artes aplicadas) e a organização social (a cultura do artesanato). Entretanto, a utopia social progressista que inspirou William Morris estava distante do tradicionalismo de Marianno e do movimento neocolonial (PINHEIRO, 20II, p. 20).

Outra aproximação sugerida por Mascaro, Bortolucci e Lourenço (20II) é entre a obra de Marianno Filho e o movimento tradicionalista em Portugal, baseado em A Casa Portuguesa. Kessel (2008, p. I78-I8I) apresenta as críticas de Marianno a esse movimento liderado por Raul Lino (I879-I974) e Ricardo Severo (I864-I940).

Ricardo Severo, protagonista do movimento tradicionalista em Portugal e reconhecido pela maioria dos autores como introdutor do neocolonial no Brasil, apresenta ainda uma perspectiva peculiar em relação a Marianno. Como apontado por Mello (2007, p. I2I): “(...) o engenheiro tinha pretensões de firmar uma aliança luso-brasileira de ajuda mútua que assegurasse 'desenvolvimento e progresso, dentro do concerto mundial' a Portugal e ao Brasil com a ajuda do continente africano (...)”.

Ao contrário de Severo, o projeto de Marianno não teve o objetivo de fortalecer uma aliança geopolítica entre Brasil e Portugal, mas inseriu-se no projeto cultural nacionalista das elites brasileiras que se afirmavam no setor produtivo, diversificando cada vez mais sua atuação e concorrendo com as empresas estrangeiras que operavam no Brasil.

A arquitetura tradicionalista defendida por José Marianno Filho é parte da formação do nacionalismo brasileiro do século XX - embora haja correspondências com os processos que originaram o projeto internacionalista de Morris, ou mesmo com a utopia da aliança luso-brasileira que animava Ricardo Severo e, ainda, com a aspiração por uma hegemonia continental americana, como a difusão do mission 
style no projeto pan-americanista - as duas últimas também reunidas no "estilo neocolonial" praticado no Brasil.

O modelo da casa tradicional brasileira foi baseado na arquitetura do século XVIII, e incluiu os temas caros às principais narrativas sobre a formação brasileira, como a cultura, a raça e o clima. Esses elementos, que aparecem nas narrativas consagradas sobre a formação brasileira de Vianna (I883-I95I), Freyre (I900-I987) e Holanda (I902-I982), estão presentes nos textos de Marianno (I88I-I946), que os formula nos anos I920, como parte de uma teoria original sobre a produção cultural do habitat brasileiro (MARIANNO, I925; I926; I927; I929; CONSELHO...I926).

\section{A casa e a cidade brasileira}

(...) apesar de nossa situação geográfica e dos rigores do clima, caminhamos bravamente para a civilização. Nossa cidade, que possui por um favor divino tudo o que as outras cidades desejariam possuir, não deve perder nenhum de seus característicos individuais. Para sermos nós mesmos precisamos viver dentro da tradição nacional da raça, sem a preocupação ridícula de copiarmos outros povos (MARIANNO, I926, p. 2).

O termo "fisionomia", emprestado de sua formação em medicina, define para ele a noção de estilo e permite identificar cultura e raça, colocando sua teoria sobre a arquitetura tradicional no centro do debate nacionalista dos anos de I920. Afirma que "a arte tem raízes profundas na alma da raça, vive de sua seiva, alimenta-se de seu sangue." (MARIANNO, I927, p. 4).

Para Marianno, o "cenário tropical violentamente recortado está a exigir uma arquitetura envolvente, ajustada à moldura do quadro da paisagem”. Uma integração que nove anos depois seria interpretada por Sérgio Buarque de Holanda (I936, p. 76) em Raízes do Brasil como uma negatividade da herança Ibérica, descrita no capítulo "o semeador e o ladrilhador" nos moldes de uma comparação entre a herança colonial espanhola e a portuguesa na América.

Marianno considerava a arquitetura parte do ambiente, por isso mesmo se dedicou ao urbanismo, procurando controlar o desenvolvimento da cidade. Em I928, Marianno afirmava que o Rio de Janeiro precisava de um urbanista profissional para planejar o crescimento da cidade. Para ele, a natureza tropical deveria realçar as qualidades estéticas e funcionais do município.

Marianno participou ativamente da Comissão de Estudos de Melhoramentos Urbanos da gestão de Alaor Prata (I922-I926), e promoveu um importante debate sobre a modernização urbana do Rio de Janeiro, escrevendo vários artigos sobre a questão ambiental na cidade. No primeiro, Marianno alerta para o problema das florestas nos morros cariocas, "barbaramente" ameaçadas pela expansão urbana. A matéria descreve a paisagem natural como o "espetáculo diário do manto de opulenta verdura que veste os morros e as colinas que envolvem em carinhoso abraço os vales estreitos que se comprimem entre as colinas e o mar". Acrescenta que a floresta "é para nós, tapuyas, um prato da casa. Nascemos entre as árvores, 
crescemos entre elas, ouvindo-lhes a música da ramaria densa”. Conclui esse artigo defendendo uma legislação ambiental que seria regulamentada apenas na década de I960 (MARIANNO, I928a, I928b, I928c).

"Os poderes públicos (federais ou municipais) deveriam desapropriar por utilidade pública (para reflorestar convenientemente) os morros a partir de 50 metros de cumiada, e os terrenos julgados necessários à formação da defesa do manto verde da cidade." (MARIANNO, I928a, p.3).

No ano seguinte, Marianno trava uma polêmica com Carlos Sampaio, que havia sido prefeito do Rio de Janeiro entre I922-I926. A polêmica foi motivada pelas críticas de Sampaio ao Plano de Alfred Agache para o Rio de Janeiro, e está registrada em um conjunto de sete artigos, intitulados “Urbanite Aguda”, reunidos em forma de livro no mesmo ano. Marianno acusou Sampaio de alinhar-se à "engenharia civil oficial", que vinha dificultando os trabalhos da missão Agache no Rio de Janeiro, "embaraçando-lhe os estudos e antecipando a falência técnica do plano” (MARIANNO, I929).

As preocupações ambientais de Marianno, bem como seu interesse arqueológico pelo passado, não eram comportamentos estranhos à monarquia portuguesa, mas foram elementos mobilizados para a atualização de um projeto de modernização conservadora que garantia ao passado um lugar no futuro da nação. Marianno enfrentava assim, sem preconceitos, os temas mais sensíveis à modernização da cidade, como a expansão da mancha urbana, a ocupação das encostas dos morros e a verticalização. Em seu discurso aos formandos de I927, ele reconhece, na tipologia vertical, uma vantagem que deveria ser tratada sob os mesmos princípios de sinceridade que garantem a boa arquitetura (MARIANNO, I927).

Em I928, Marianno retoma o tema da verticalização da cidade ao apresentar um relatório em nome da sessão técnica de Morfologia e Estética da Comissão de Urbanismo, em que propôs restrições à verticalização do Rio de Janeiro, visando "acautelarmos os interesses estéticos da cidade, disposta a adotar um gênero de arquitetura exótica”. Mesmo desaprovando a disseminação de arranha-céus na cidade, Marianno mostrou-se disposto a limitar, e não impedir, a arquitetura vertical.

\section{Considerações finais}

José Marianno Filho produziu uma interpretação do Iberismo na arquitetura brasileira como elemento primitivo da formação nacional, parte de um projeto específico de modernização original e autônomo. A arquitetura tradicional, por meio da casa brasileira, e sua integração com a paisagem da cidade colonial foram a base cultural e artística desse projeto. Esses elementos do Iberismo apresentados por José Marianno Filho foram também abordados por Freyre (I933) e Holanda (I936) em suas interpretações da cultura brasileira na formação do caráter nacional. A explicitação do debate sobre a casa e a cidade brasileira nesse movimento contribui para uma leitura do ambiente como produção cultural e social dentro da discussão sobre a nacionalidade.

As matérias publicadas em $O$ Jornal na década de 20 apresentam sua interpretação da cultura brasileira. A casa tradicional brasileira resultava de um sistema cultural 
completo, que relacionava o homem e o meio através da arquitetura. Esta, por sua vez, produzia a paisagem urbana, que se entrelaçava em uma relação cuja harmonia evidenciava a existência de uma cultura original e autêntica.

Marianno não tratou do tema dos escravizados, uma das grandes questões políticas do período republicano. Também não pretendeu denunciar a colonização portuguesa como uma obra de exploração baseada no exclusivo colonial, no latifúndio monocultor e escravista. Suas questões foram ligadas à defesa do passado como elemento da tradição de uma cultura nacional de elite. Portanto, a centralidade da casa como elemento cultural capaz de garantir e atualizar a manutenção de valores patrimoniais das elites locais contra um processo de modernização cosmopolita em disputa nas décadas de 20 e 30.

$\mathrm{O}$ artigo procurou demonstrar a relevância do projeto cultural de Marianno na renovação política das elites brasileiras a partir de suas conexões com Assis Chateubriand e Fernando de Azevedo. Evidenciou que interpretações sobre a casa e a cidade brasileira que comparecem na obra de Freyre e Holanda nos anos I930 foram formuladas por Marianno ainda nos anos I920. Que o movimento de renovação do passado ibérico na "arquitetura tradicional brasileira" foi uma vertente específica do movimento neocolonial, em certa medida distinto daquele de Ricardo Severo e explicitamente oposto ao estilo "missões", também identificado como "neocolonial". Podemos explicar os diferentes significados da renovação do passado ibérico no movimento neocolonial, adotando-se a explicação dada por Oliveira (I990, p. I87) de que esses significados diferentes atribuídos ao passado expressam "diferentes visões sobre o que (...) deveria ser a nação" durante o período republicano. Por fim, evidenciamos que Marianno, em seu projeto tradicionalista, já identificava civilização e estilo, artes menores, arquitetura e paisagem, fornecendo os elementos fundamentais presentes na narrativa nacionalista do modernismo brasileiro.

SOBRE O AUTOR

Ana Koury Arquiteta e Urbanista. Pós Doutora pelo Instituto de Estudos Brasileiros da USP. Professora da pós graduação stricto sensu da Universidade São Judas e Professora dos cursos de graduação em arquitetura e urbanismo da Universidade São Judas e da Universidade Presbiteriana Mackenzie.

E-mail: ana.koury@saojudas.br

https://orcid.org/my-orcid=0000-0002-546I-4994 


\section{REFERÊNCIAS}

A CASA BRASILEIRA: Conferência do Dr. José Marianno Filho. O Jornal, Rio de Janeiro, 2I jun. I924, p. 3. AMARAL, Aracy. Arquitectura Neocolonial: América Latina, Caribe e Estados Unidos. São Paulo: Memorial, Fondo de Cultura Económica, I994.

ATIQUE, Fernando. Arquitetando a "Boa Vizinhança”: Arquitetura, Cidade e Cultura nas Relações Brasil -Estados Unidos I876-I945. São Paulo: Pontes Editores/Fapesp, 2010.

ATIQUE, Fernando. “De Casa Manifesto a Espaço de Desafetos: Os Impactos Culturais, Políticos e Urbanos Verificados na Trajetória do Solar Monjope (Rio, anos 20 - anos 70)”. Revista Brasileira de História, v. 29, n. 57, 20I6, p. 2I5-234.

AZEVEDO, Fernando. A Cultura Brasileira. Instituto Brasileiro de Geografia e Estatística, I943.

AZEVEDO, Fernando. "Arquitetura colonial”. O Estado de São Paulo, 30 abr. I926, p. 4. Disponível em: http://acervo.estadao.com.br/pagina/\#!/I9260430-I7229-nac-0004-999-4-not/busca/architectura+colonial+sobre+Inqu\%C3\%A9rito. Acesso em: 2 maio 2018.

BANDEIRA, Julio. Solar de Monjope. Rio de Janeiro: Reler, 2008.

BASTOS, Élide Rugai. “Gilberto Freyre: Casa Grande e Senzala”. In: MOTA, Lourenço Dantas. Introdução ao Brasil: Um Banquete no Trópico. São Paulo: SENAC, 2000. v. I, p. 2I5-234.

BRUAND, Yves. Arquitetura Contemporânea no Brasil. São Paulo: Perspectiva, I98I.

CHATEAUBRIAND, Assis. "Pela Beleza das Habitações da Cidade”. O Jornal, Rio de Janeiro, 28 jan. I926a, p. 2. CHATEAUBRIAND, Assis. “A Arte de Viver Confortavelmente”. O Jornal, Rio de Janeiro, 8 jun. I926b, p. I. CHATEAUBRIAND, Assis. “A Escola de Belas Artes”. O Jornal, Rio de Janeiro, 7 jun. I927, p. 2. CHATEAUBRIAND, Assis. “A Questão das Inundações”. O Jornal, Rio de Janeiro, 29 fev. I928, p. 2. CONSELHO de Ensino Secundário e Superior. O Jornal, Rio de Janeiro, 2 nov. I926, p. 2.

FREYRE, Gilberto. Casa Grande e Senzala: Formação da Família Brasileira sob o Regime da Economia Patriarcal. I9. ed. Rio de Janeiro: José Olympio, I978.

GUERRA, Abílio. O Primitivismo em Mário de Andrade, Oswald de Andrade e Raul Bopp. Origem e Conformação no Universo Intelectual Brasileiro. São Paulo: Romano Guerra, 2010.

HOLANDA, Sérgio Buarque. Raízes do Brasil. Rio de Janeiro: José Olympio, I98I.

KESSEL, Carlos. Arquitetura Neocolonial no Brasil: entre o Pastiche e a Modernidade. Rio de Janeiro: Jauá Editora, 2008.

MAIOR, Mário Souto; SILVA, Leonardo Dantas. A Paisagem Pernambucana. Recife: Fundação Joaquim Nabuco/Massangana, I993, p. 76.

MARIANNO FILHO, José. “Architectura Tradicional”. O Jornal. Rio de Janeiro, 30 maio I92Ia, p. I.

MARIANNO FILHO, José. “Estudos de Arquitetura Brasileira: Prêmios Instituídos pelo dr. José Marianno Filho". O Jornal. Rio de Janeiro, 4 jun. I92Ib, p. 3.

MARIANNO FILHO, José. “Impressões do Salão”. O Jornal, Rio de Janeiro, I6 set. I925, p. I.

MARIANNO FILHO, José. "Porque Precisamos de um “Town-planner". O Jornal, Rio de Janeiro, 27 nov. I926, p. 2.

MARIANNO FILHO, José. “A Colação de Grau dos Engenheiros-Arquitetos da Escola Nacional de Belas Artes”. O Jornal, Rio de Janeiro, 7 jun. I927, p. 4.

MARIANNO FILHO, José. “A Cintura Verde da Cidade”. O Jornal, Rio de Janeiro, 4 fev. I928a, p. 3. MARIANNO FILHO, José. “A Questão das Inundações”. O Jornal, Rio de Janeiro, 29 fev. I928b, p. 2. MARIANNO FILHO, José. “A Mutilação de Nossos Jardins”. O Jornal, Rio de Janeiro, 4 mar. I928c. MARIANNO FILHO, José. “Decálogo do Arquiteto Brasileiro”. O Jornal, Rio de Janeiro, 22 dez. I929a, p. 3. MARIANNO FILHO, José. “38 à Sombra”. O Jornal, Rio de Janeiro, 29 dez. I929b, p. I. 
MARIANNO FILHO, José. Urbanite Aguda. Rio de Janeiro: Empreza Graphica Paulo Pongetti \& Cia., I929c. (Publicados originalmente em O Jornal em I, 8, I3, I6, 20, 27 e 29 de março de I929. A resposta de Carlos Sampaio foi publicada em 28 de março).

MASCARO, Luciana Pelaes; BORTOLUCCI, Maria Ângela; LOURENÇO, Júlia Maria. "Ricardo Severo, Raul Lino e os Movimentos Tradicionalistas”. RCL Convergência Lusíada, n. 25, jan./jun. 20II, p. IO2-I23.

MELLO, Joana. Ricardo Severo: da Arqueologia Portuguesa à Arquitetura Brasileira. São Paulo: AnnaBlume/ Fapesp, 2007.

MINGORANCE, Wilson Ricardo. "Leituras de José Marianno Filho sobre a Arte, a Arquitetura e a Cidade do Século XIX no Brasil”. Ige22o, Rio de Janeiro, v. VIII, n. I, jan./jun. 20I3. Disponível em: http://www. dezenovevinte.net/criticas/la_jmarianno.htm. Acesso em: 8 ago. 202I.

NOGUEIRA, Marco Aurélio. Positividades e Negatividades da Herança Ibérica: Oliveira Vianna e Sérgio Buarque de Holanda. São Paulo: Cultura CPFL, 2003. I DVD (50 min.): son., color (Intérpretes do Brasil no século XX).

OLIVEIRA, Lucia Lippi. A Questão Nacional na Primeira República. São Paulo: Brasiliense, I990.

PEVSNER, Nicolaus (1936). Pioneiros do Desenho Moderno. São Paulo: Martins Fontes (Pioneers of the modern movement, I936 - Pioneers of Modern Design 1949).

PILETTI, Nelson. "A Reforma da Educação Pública no Distrito Federal, I927-I930: Algumas Considerações Críticas”. Revista da Faculdade de Educação, v. 20, n. I-2, I994, p. I07-I3I.

PINHEIRO, Maria Lúcia Bressan. "A História da Arquitetura Brasileira e a Preservação do Patrimônio Cultural”. Revista do CPC, São Paulo, v.I, n.I, p. 4I-74, nov. 2005-abr. 2006.

PINHEIRO, Maria Lúcia Bressan. Neocolonial, Modernismo e Preservação do patrimônio no debate cultural dos anos I920 no Brasil. São Paulo: Edusp, 2011.

PINHEIRO, René Thiollier. Obra e Vida do Grão-senhor da Villa Fortunata e da Academia Paulista de Letras. São Paulo: Atelier Editorial, 2017.

PUPPI, Marcelo. Por Uma História não Moderna da Arquitetura Brasileira. Campinas: Pontes Editores, I998.

SANTOS, Paulo Ferreira. Quatro Séculos de Arquitetura. I. ed. Barra do Piraí: Fundação Educacional Rosemar Pimentel, I977.

SCHUMAHER, Schuma; BRAZIL, Érico Vital. Dicionário Mulheres do Brasil de I50o até a Atualidade. Rio de Janeiro: Zahar, 2000.

SOLAR DO MONJOPE. O Jornal. Rio de Janeiro, 30 jul. I927.

TELLES, Augusto da Silva. “Neocolonial: La Polémica de José Marianno”. In: AMARAL, Aracy. Arquitectura Neocolonial: América Latina, Caribe e Estados Unidos. São Paulo: Memorial, Fondo de Cultura Económica, I994, p. 237-248.

VIEIRA, Lucia Gouvêa. Salão de I93I: Marco da Revelação da Arte Moderna em Nível Nacional. Rio de Janeiro: FUNARTE/Instituto Nacional de Artes Plásticas, I984.

WESTLAND, Peter. The Romantic Revival I780-I830. Londres: The English Universities Press, I950.

WORRINGER, Wilhem. El Arte y Sus Interrogantes. Buenos Aires: Editorial Nueva Vision, I959. 